\title{
Relationship of T1 Slope with sagittal alignment parameters of the upper and subaxial cervical spine in patients with cervical lordotic and kyphotic curvature
}

\author{
Dong Sun \\ China-Japan Union Hospital of Jilin University \\ Peng Liu ( $\square$ 844795606@qq.com ) \\ China-Japan Union Hospital of Jilin University \\ Zhaolin Wang \\ China-Japan Union Hospital of Jilin University \\ Jie Cheng \\ China-Japan Union Hospital of Jilin University \\ Jianhui Mou \\ China-Japan Union Hospital of Jilin University \\ Yipeng Wang \\ China-Japan Union Hospital of Jilin University \\ Fenghua Tian \\ China-Japan Union Hospital of Jilin University \\ Shuang Liu \\ China-Japan Union Hospital of Jilin University \\ Hongmei Bao \\ China-Japan Union Hospital of Jilin University \\ Na Sun \\ China-Japan Union Hospital of Jilin University
}

Research article

Keywords: T1 slope, Upper cervical spine, Subaxial cervical spine, T1 slope minus cervical lordosis, Compensatory mechanism

Posted Date: August 20th, 2020

DOI: https://doi.org/10.21203/rs.3.rs-26626/v2

License: (c) (1) This work is licensed under a Creative Commons Attribution 4.0 International License. Read Full License 


\section{Abstract}

Background: To identify the relationship between T1 slope and the sagittal alignment parameters of the upper and subaxial cervical spine in patients with cervical lordosis and kyphosis.

Methods: Relevant sagittal radiographic parameters pertaining to patients with non-specific neck pain but with no associated neurogenic symptoms were retrospectively analyzed. Patients were categorized into lordotic alignment and kyphotic alignment groups based on the C2-C7 Cobb. Correlation among radiographic variables was assessed with the Pearson correlation coefficient and linear regression analysis. Between-group differences with respect to cervical alignment parameters were assessed with One-way Analysis of Variance.

Results: Intra-observer and inter-observer agreement (two independent observers) was rated as excellent (kappa: 0.91 - 0.93). Inter-observer agreement for the two independent observers was rated as and substantial (kappa: $0.79-0.80$ ), respectively. Significant between-group differences were observed with respect to $\mathrm{C} 0-\mathrm{C} 1$ angle, $\mathrm{C} 1-\mathrm{C} 2$ angle, C0-C2 angle, C2-C7 SVA (sagittal vertical axis) and TS-CL (T1 slope minus cervical lordosis) ( $\mathrm{P}<0.01 \mathrm{for}$ all), but not with respect to T1S (T1 slope) $(P=0.367)$. In both groups, C2-C7 SVA showed a significant linear correlation with T1S $\left(r^{2}=0.712\right.$ vs. $\left.r^{2}=0.467\right)$ and TS-CL $\left(r^{2}=0.810 v s\right.$. $\left.r^{2}=0.248\right)$

Conclusion: This study showed that the two cervical alignment types (lordosis and kyphosis) have different angular variation in upper and subaxial cervical spine. With the increase in T1 slope, the upper cervical C0-C2 Cobb angle and the C2-7 SVA in the lordotic group were significantly higher than that of the kyphotic group. TS-CL mismatch may significantly impact lordotic cervical alignment in patients with lordosis.

\section{Background}

The occipital-atlantoaxial complex, also referred to as the transition zone between the occipital condyle and the lower cervical spine, is a remarkably complex segment and a unique "special" structure in the skeletal system [1]. It not only plays an important role in the maintenance of head stability and allows the widest range of movements relative to the rest of the spine, but also benefits preoperative planning[2,3].

The intricacies of cervical alignment make it more susceptible to a variety of disorders[4]. Till now, various aspects of cervical alignment have been described in the published literature. Lee et al [4] reported the use of T1 slope to predict physiological cervical alignment. Knott[5] emphasized the close association between the T1 slope and spinal sagittal balance. According to the authors, patients in whom the T1 slope is outside the range of $13^{\circ}-25^{\circ}$ should undergo fullcolumn radiographs for a complete evaluation of sagittal balance. Ordway[6] and Tetsuo[1] have shown the compensatory role of upper and lower cervical spine motion, especially that of the $\mathrm{Oc}-\mathrm{C} 1$ segment.

Spinal fusion, over the past 50 years, has become a standard surgical treatment for cervical spondylosis[17]. In order to avoid adjacent segment problems, more attention should be paid to the compensatory mechanisms that maintain sagittal alignment of the upper and subaxial cervical spine. This is especially important in patients with cervical kyphosis following occipital-atlantoaxial fusion.

However, the relationship between T1 slope and the sagittal alignment parameters of the upper and subaxial cervical spine in patients with cervical lordosis and kyphosis is not well-characterized. Considerable ambiguity persists as to whether this special relationship holds for determining the compensatory mechanism in different cervical alignment types (Iordosis and kyphosis)[2]. We hypothesized that the relationship between T1 slope and sagittal alignment in patients with lordotic cervical curvature differs from that in patients with kyphotic cervical curvature, and that the special relationship holds true for upper and subaxial cervical segments in the context of kyphotic cervical spine.

The purpose of this study, therefore, was to further clarify the association between T1 slope and sagittal alignment parameters of the upper and lower cervical spine in patients with lordotic and kyphotic curvature by retrospective radiographic analysis.

\section{Methods}

\section{Patients}

Data pertaining to patients who underwent cervical radiography for non-specific neck pain between March 2015 and August 2015 at the local Hospital were retrospectively analyzed. Inclusion criteria were: absence of neurogenic symptoms such as myelopathy or radiculopathy and no effect of pain on activities of daily living or on participation in recreational activities. The exclusion criteria included presence of neurogenic symptoms, malignancies, infection, scoliosis, ankylosing spondylitis, fractures, diffuse idiopathic skeletal hyperostosis, or global sagittal alignment deformity. The study was approved by the Institutional Review Board.

\section{Radiographic positioning}

All patients underwent lateral radiograph of cervical spine with horizontal gaze in standing position. Upper limbs were positioned naturally on both sides of the body. Vertically, the area coverage was from the orbit to the third thoracic vertebra, and from the maxilla to the occiput horizontally. Maintenance of horizontal gaze as measured by CBVA (Chin brow vertical angle) between $-5^{\circ}$ and $17^{\circ}$, McGregor's slope between $-6^{\circ}$ and $14^{\circ}$ or slope of lines of sight (SLS) between $-5.1^{\circ}$ and $18.5^{\circ}[7,8]$ allow for maintenance of horizontal gaze. The Cobb angle of C2-7 was used to indicate lordotic and kyphotic curvature of the cervical spine.

\section{Data Collection and radiographic measurements}


Demographic data including age, gender, BMI, and duration of pain were collected. The data obtained from standard lateral cervical x-ray images were extracted, and exported to the PACS system for analysis at our institution. Additionally, the following sagittal radiographic parameters were evaluated:

- $\mathrm{C} 0-\mathrm{C} 1$ curve (CO-C1COBB): the angle between occipital foramen line and $\mathrm{C} 1$ anterior and posterior tubercle line. A positive value denotes lordosis.

- $\mathrm{C} 1-\mathrm{C} 2$ curve (C1-C2COBB): the angle between $\mathrm{C} 1$ tubercle line and lower endplate of $\mathrm{C} 2$. A positive value denotes lordosis.

- Upper cervical sagittal curve (C0-C2COBB): the angle between occipital foramen line and lower endplate of C2. A positive value denotes lordosis.

- subaxial cervical sagittal curve (C2-C7COBB): the angle between the lower endplate of $\mathrm{C} 2$ and $\mathrm{C7}$. A positive value denotes lordosis.

- C2-C7 sagittal vertical axis (C2-C7SVA): the horizontal offset of a plumb line dropped from the center of $\mathrm{C} 2$ vertebral body to the center of C7 vertebra.

- T1 slope: the angle between a horizontal line and the superior endplate of T1. A positive value denotes open back.

- T1 slope minus cervical lordosis (TS-CL):

- Chin brow vertical angle (CBVA): the angle subtended between a line from the brow to the chin and the vertical plane.

- McGregor slope (McGS): the angle between the line from the posterosuperior aspect of the hard palate to the caudal aspect of the opisthion and the horizontal plane.

- Slope of line of sight (SLS): the angle between Frankfurt line and the horizontal (Figure 1).

\section{Statistical methods}

Statistical analysis was conducted with SPSS software (version. 21.0, SPSS IBM, Armonk, NY). Data pertaining to continuous variables is expressed as mean \pm standard deviation (SD).

Two spine surgeons independently performed the measurements twice to determine intra- and inter-observer reliability of radiographic parameters. There was at least a 2 weeks interval between the two measurements by the same surgeon. All measurements were carried out using a picture-archiving and communication system. Intra-observer reproducibility of radiographic parameters was assessed using weighted Kappa statistics.

In order to generate linear regression models, correlation between radiographic variables was assessed with the Pearson correlation coefficient and linear regression analysis.

Cervical radiographic parameters between the two groups were compared with one-way Analysis of Variance (ANOVA). A $P$ value of $<0.05$ was considered statistically significant.

\section{Results}

A total of 610 patients (309 men and 301 women; mean age: 42.18 years [range, 18-76]) qualified the inclusion criteria. Of these, 507 (83.1\%) patients (256 men and 251 women) maintained horizontal gaze with lordotic cervical alignment. The mean age of these patients was 43.38 ( \pm 13.88 ) years (range, 18-76); mean BMI was $26.5 \pm 5.2 \mathrm{~kg} / \mathrm{m}^{2}$ (mean weight: $72.3 \pm 20.5 \mathrm{~kg}$; mean height: $1.65 \pm 0.15 \mathrm{~m}$ ). The remaining 103 patients (16.9\%) maintained horizontal gaze with kyphotic cervical alignment. These patients were significantly younger (age: $36.23 \pm 13.45$ years vs. $43.38 \pm 13.88$ years, $P<0.001$ ) than those with lordotic cervical alignment, and had lower BMI (24.4 vs. $\left.26.5 \mathrm{~kg} / \mathrm{m}^{2}, \mathrm{P}<0.01\right)$; however, the sex distribution was comparable between the two groups (proportion of females: $49.5 \%$ vs. $50.4 \%$, respectively).

'Excellent' intra-observer agreement was observed for both observers ( kappa:C0-C1 COBB 0.90, C1-C2 COBB 0.91, C2-C7COBB 0.91, C2-C7SVA 0.93, T1 slope 0.90, TS-CL 0.91, CBVA 0.93, McGS 0.90, SLS 0.90), while inter-observer agreement was rated as 'substantial' (kappa: C0-C1 COBB 0.79, C1-C2 COBB 0.80, C2C7COBB 0.78, C2-C7SVA 0.83, T1 slope 0.79, TS-CL 0.81, CBVA 0.83, McGS 0.81, SLS 0.81).

Radiographic parameters in the cervical lordosis and kyphosis groups along with the results of one-way ANOVA are presented in Table 1 and Figure 2. Significant between-group differences were observed with respect to $C 0-C 1$ angle $(P<0.01), C 1-C 2$ angle $(P<0.01), C 0-C 2$ angle $(P<0.01), C 2-C 7$ SVA $(P<0.01)$ and TS-CL $(P<0.01)$. However, no significant difference was observed with respect to T1S $(P=0.367)$.

Table 1. Results of the one-way Analysis of Variance of the radiographic parameters

$*: \mathrm{P}<0.01$; data presented as mean \pm standard deviation

T1S:T1 slope; TS-CL:T1 slope minus cervical lordosis; SVA, sagittal vertical axis

The correlation of radiographic parameters among patients with different cervical alignment types (lordosis and kyphosis) are summarized in Tables 2 and 3 , respectively. A significant positive correlation was observed between age and C2-C7Cobb in the cervical lordosis group ( $r=0.159 ; P=0.002)$, but not in the kyphosis group $(r=0.12 P=0.312)$. T1S showed a significant correlation with C0-C1Cobb and C1-C2Cobb $(r=-0.255, P<0.001 ; r=0.168, P=0.001)$, but not with C0$\mathrm{C} 2 \mathrm{Cobb}(\mathrm{r}=0.009, \mathrm{P}=0.969)$. However, in the cervical kyphosis group, a significant positive correlation was observed between $\mathrm{C} 0-\mathrm{C} 2 \mathrm{Cobb}$ and $\mathrm{T} 1 \mathrm{~S}$ ( $\mathrm{r}=0.277$ $\mathrm{P}=0.018)$. The $\mathrm{C} 2-\mathrm{C} 7 \mathrm{Cobb}$ showed a significant correlation with T1S in lordotic groups $(r=0.289, \mathrm{P}<0.001 ; \mathrm{r}=0.684, \mathrm{P}=0.018)$.

Table 2. Results of Pearson correlation analysis showing correlation between radiographic parameters in the Lordotic group 


\begin{tabular}{|c|c|c|c|c|c|c|c|c|c|c|c|c|}
\hline Sagittal parameters & Lordotic & Kyphotic & ANOVA & & \multirow{2}{*}{\multicolumn{2}{|c|}{$\begin{array}{l}\text { AgeC0- } \\
\qquad \text { С1СОвB }\end{array}$}} & \multirow{2}{*}{$\begin{array}{l}\text { C1- } \\
\text { С2СОВB }\end{array}$} & \multirow{2}{*}{$\begin{array}{l}\mathrm{C} 0- \\
\mathrm{C} 2 \mathrm{COBB}\end{array}$} & \multirow{2}{*}{$\begin{array}{l}\mathrm{C} 2- \\
\mathrm{C} 7 \mathrm{COBB}\end{array}$} & \multirow{2}{*}{$\begin{array}{l}\text { C2- } \\
\text { C7SVA }\end{array}$} & \multirow[t]{2}{*}{ T1S } & \multirow{2}{*}{$\begin{array}{l}\text { T1S- } \\
\text { CL }\end{array}$} \\
\hline Age & $43.34 \pm 13.88^{*}$ & $36.23 \pm 13.45$ & $(\mathrm{~F}=16.18 \quad P<0.001)$ & & & & & & & & & \\
\hline \multirow{2}{*}{ C01Cobb } & \multirow{2}{*}{$4.90 \pm 4.78^{*}$} & \multirow{2}{*}{$7.22 \pm 5.79$} & \multirow{2}{*}{$(\mathrm{F}=13.35 P<0.001)$} & Age & 1 & .061 & .018 & .051 & $.159^{* *}$ & -.015 & .040 & -.092 \\
\hline & & & & $\mathrm{C} 0-$ & & 1 & -.028 & $.559^{* *}$ & -.070 & .010 & $-.255^{* *}$ & $*-159^{* *}$ \\
\hline C12Cobb & $26.72 \pm 6.80^{*}$ & $29.95 \pm 5.79$ & $(\mathrm{~F}=13.43 P<0.001)$ & С1СовB & & & & & & & & \\
\hline C02Cobb & $31.62 \pm 8.20^{*}$ & $37.08 \pm 9.60$ & (F=25.54 $P<0.001 \square$ & $\begin{array}{l}\text { C1- } \\
\text { C2COBB }\end{array}$ & & & \multirow[t]{2}{*}{1} & $.813^{* *}$ & $-.208^{* *}$ & $.276^{* *}$ & $.168^{* *}$ & $.316^{* *}$ \\
\hline C27SVA & $13.20 \pm 10.30^{*}$ & $17.32 \pm 10.29$ & $(\mathrm{~F}=10.27 \quad P<0.001)$ & $\begin{array}{l}\mathrm{C} 0- \\
\mathrm{C} 2 \mathrm{COBB}\end{array}$ & & & & 1 & $-.213^{* *}$ & $.235^{* *}$ & .009 & $.169^{* *}$ \\
\hline \multirow[t]{3}{*}{ TSCL } & $19.7 \pm 10.81$ & $20.79 \pm 7.71$ & $(\mathrm{~F}=0.817 \quad P=0.367)$ & $\begin{array}{l}\mathrm{C} 2- \\
\mathrm{C} 7 \mathrm{COBB}\end{array}$ & & & & & 1 & $-.209^{* *}$ & $.289^{* *}$ & $-.567^{* *}$ \\
\hline & \multirow[t]{2}{*}{$1.79 \pm 12.45^{*}$} & \multirow[t]{2}{*}{$21.16 \pm 10.23$} & \multirow[t]{2}{*}{$(\mathrm{F}=162.44 P<0.001)$} & C2-C7SVA & & & & & & 1 & $.845^{* *}$ & $.900^{* *}$ \\
\hline & & & & T1S-CL & & & & & & & & 1 \\
\hline
\end{tabular}

*: $\mathrm{P}<0.05 ; * *: P<0.01$

T1S:T1 slope; TS-CL:T1 slope minus cervical lordosis; SVA, sagittal vertical axis

On linear regression analysis, statistically significant linear regression models were established (Figure 3). There was a significant linear correlation between C2-C7 SVA and T1S ( ${ }^{2}=0.712$ vs. $\left.r^{2}=0.467\right)$, and between C2-C7SVA and TSCL $\left(r^{2}=0.810\right.$ vs. $\left.r^{2}=0.248\right)$.

Table 3. Results of Pearson correlation analysis showing correlation between radiographic parameters in the Kyphotic group

\begin{tabular}{|c|c|c|c|c|c|c|c|}
\hline & \multicolumn{7}{|c|}{ AgeC0-C1COBВC1-C2СОВBC0-C2СОВBC2-C7COBВC2-C7SVA T1S T1S-CL } \\
\hline & 1.006 & -.028 & -.007 & -.120 & .035 & .016 & .103 \\
\hline COBB & 1 & .062 & $.647^{* *}$ & .095 & .129 & .164 & .051 \\
\hline :COBB & & 1 & $.797^{* *}$ & -.031 & .219 & $.238^{*}$ & .202 \\
\hline :COBB & & & 1 & .033 & $.251^{*}$ & $.277^{*}$ & .183 \\
\hline 'COBB & & & & 1 & .023 & .126 & $-.664^{* *}$ \\
\hline 'SVA & & & & & 1 & $.684^{*}$ & *.498** \\
\hline :L & & & & & & 1 & $\begin{array}{l}.659^{* *} \\
1\end{array}$ \\
\hline
\end{tabular}

*: $\mathrm{P}<0.05 ; * *: P<0.01$

T1S:T1 slope; TS-CL:T1 slope minus cervical lordosis; SVA, sagittal vertical axis

\section{Discussion}

In this study, we clarified the association between T1 slope and sagittal alignment parameters of the upper and lower cervical spine in patients with lordotic and kyphotic curvature by retrospective radiographic analysis. Results of the present study support the hypothesis that the relationship between T1 slope and sagittal alignment in patients with lordotic cervical curvature differs from that in patients with kyphotic cervical curvature, and that the special relationship holds true for upper and subaxial cervical segments of kyphotic cervical spine. The cervical spine plays an important role in total spinal sagittal alignment by means of compensatory mechanism to maintain the horizontal gaze. There is, therefore, an obvious need to accurately characterize the cervical deformity and distinguish it from cervical compensation for thoracolumbar and cervical alignment. Although cervical kyphosis, often interpreted as indicative of cervical deformity, is an increasingly prevalent phenomenon, studies have shown that cervical kyphosis in up to $30 \%$ of patients may be a component of normal sagittal spinal alignment. $[9,10]$ In other words, the presence of kyphotic cervical alignment in some patients may indicate substantial deformity and be linked to poor clinical outcomes, while in others, the kyphotic cervical alignment may be appropriate given the patient's global and thoracic sagittal alignment.

The compensatory mechanism of upper and lower cervical spine during cervical motion at weight-bearing neutral, flexion and extension positions is welldocumented in previous studies $[1,6]$. These studies have indicated that the decreased movement at the lower cervical spine, caused by intervertebral disc degeneration was compensated for by increased angular movement of the upper cervical spine, and especially that of Oc-C1. However, owing to different T1 slope in patients with lordotic and kyphotic curvature, the compensatory sagittal alignment of upper and lower cervical spine is still unclear. We hypothesized that compensatory mechanisms differ based on the cervical alignment (lordosis and kyphosis), and sought to examine the relationship between T1 slope and sagittal alignment parameters of the upper (Co-C2 Cobb) and subaxial (C2-C7 Cobb) cervical spine in patients with lordotic and kyphotic cervical curvature. 
In the present study, of all patients with non-specific neck pain, 103 patients (16.9\%) were able to maintain horizontal gaze with kyphotic cervical alignment. These findings differ from those of previous studies which showed that cervical kyphosis in up to $30 \%$ of patients may be a component of normal sagittal spinal alignment.[9,10]

In this study, patients with cervical kyphosis were younger than those in the lordotic group and this may be attributable to two potential reasons: Firstly, we selected patients with non-specific neck pain who had no neurogenic symptoms and required operative treatment. In these patients, cervical pain did not affect cervical activities. Secondly, there are differences between Asian and European populations, such as with respect to BMI, daily exercise, and job category. Especially in young people, the time spent working on the desk tends to be longer than that in older people. Furthermore, flattening of the thoracic spine leads to progressive cervical kyphosis. These findings were described by Yu et al [11], who found that larger curvatures in the thoracic and lumbar spines were associated with greater cervical lordosis in both symptomatic and asymptomatic patients.

We observed a negative correlation between $\mathrm{C} 2-\mathrm{C} 7 \mathrm{Cobb}$ and the T1 slope $(\mathrm{P}<0.05)$ and between $\mathrm{C} 2-\mathrm{C} 7 \mathrm{Cobb}$ and $\mathrm{C} 0-\mathrm{C} 2 \mathrm{Cobb}(\mathrm{P}<0.05)$, while no correlation was observed between $\mathrm{C} 0-\mathrm{C} 2 \mathrm{Cobb}$ and $\mathrm{T} 1$ slope $(\mathrm{P}>0.05)$ in the lordotic group. However, no significant correlation was found between $\mathrm{C} 2-\mathrm{C} 7 \mathrm{Cobb}$ and $\mathrm{T} 1$ slope and between $\mathrm{C} 2-\mathrm{C} 7 \mathrm{Cobb}$ and $\mathrm{C} 0-\mathrm{C} 2 \mathrm{Cobb}(\mathrm{P}>0.05)$ in the kyphotic group, while a significant correlation was observed between $\mathrm{T} 1 \mathrm{slope}$ and $\mathrm{C} 0-\mathrm{C} 2$ Cobb $(\mathrm{P}<0.05)$. A possible explanation for this correlation is that with increase in $\mathrm{T} 1$ slope angle, subaxial cervical spine had enough adjusting ability to maintain horizontal gaze and to compensate cervical global sagittal alignment by an increase in the C2-C7 Cobb angle in lordotic group.

In the kyphotic group, however, the limited adjusting ability of upper cervical spine induces an increase in the angle of $\mathrm{CO}$ - $\mathrm{C} 2 \mathrm{Cobb}$ in order to maintain the horizontal gaze and the total cervical sagittal alignment (C2-C7 SVA) owing to decreased adjusting ability of the subaxial cervical spine; this may be correlated with cervical muscle content, but is not clearly described in published literature. Therefore, C2-C7 SVA and C0-C2 Cobb angles in the kyphotic group were significantly greater than those in the lordotic group $(\mathrm{P}<0.05)$. The decrease in Cobb angle of the lower cervical spine is compensated by increase in Cobb angle at the upper cervical spine, especially that of $00-\mathrm{C} 2$.

Compared with previous studies, the aforementioned findings are interesting in several respects, even though these studies do not necessarily support the findings of the present study. Roussouly et al[12] described different compensatory mechanisms and proposed a three-step algorithm for the analysis of the global status (spine, pelvis and lower limb) in patients with severe degenerative lumbar spine. To maintain the horizontal gaze, cervical hyperextension above a hyperkyphosis of the thoracic spine is a typical compensatory mechanism. Consistent with our findings, Hayashi et al ${ }^{7}$ demonstrated that decreased motion at the lower cervical spine was compensated for by an increase in the angular movement of the upper cervical spine, especially that at C0-C1. Lee et al[4] reported the relationship between thoracic inlet alignment and craniocervical sagittal balance in asymptomatic adult volunteers. According to the authors, TIA and T1 slope could be used to predict the physiological cervical alignment. Yoshimoto et al[13] reported kyphotic changes in the lower cervical spine of patients with hyperlordotic C1-2 fusion angle. Matsunaga et al[14] reported the occurrence of lower cervical hyperlordosis and subaxial subluxation after C1-2 fusion of a kyphotic cervical spine in a patient with rheumatoid disease. Global alignment of spine compensates for local spinal changes in order to maintain global alignment and horizontal gaze. This may be an important factor which determines cervical fusion angle, especially in patients with cervical kyphosis.

Another interesting finding was the linear correlation of C2-C7 SVA with T1 slope in both the groups. However, in the linear regression model, T1 slope exhibited a weaker association than TS-CL; moreover, TS-CL was a stronger predictor of total cervical sagittal alignment than T1S in the lordotic group (Figure 3 ), which not only reflected the change in T1 slope, but also represented the adjusting ability of the subaxial cervical spine. In the lordotic group, the value of C2-C7 SVA gradually increased with change in T1S value $\left(R^{2}=0.712\right)$. When the subaxial cervical spine adjusted for the T1S slope by hyperlordosis, a stronger correlation was found between C2-C7 SVA and TS-CL $\left(R^{2}=0.810\right)$. However, we did not observe this trend in the kyphotic group because of the limited adjusting ability of the subaxial cervical spine. Similarly, Hyun et al [15] reported their experience with multilevel posterior cervical fusion; they examined the relationship between sagittal cervical alignment and patient-reported health-related quality-of-life scores. The authors reported that a greater T1S-CL mismatch was often accompanied by a greater degree of cervical malalignment, especially if the mismatch was greater than $26.1^{\circ}$.

In contrast to the cervical lordotic type, there is a specific correlation for upper and lower cervical segments in the kyphotic type, and the inadequate adjusting alignment of the $\mathrm{C} 0-\mathrm{C} 2 \mathrm{Cobb}$ angle was incapable of maintaining the total cervical sagittal alignment. In a similar recent study involving cervical reconstruction surgery in the thoracolumbar spine, serious instability was increased with positive sagittal malalignment[16]. We demonstrated a similar relationship between $\mathrm{C} 2-\mathrm{C} 7 \mathrm{SVA}$ and TS-CL in the lordotic group, but not in the kyphotic group.

Several limitations in this study should be recognized. Firstly, General QOL such as SF-36, VAS could not be evaluated because of the retrospective study design. Secondly, longitudinal analysis of the influence of degenerative cervical spondylosis on the upper and subaxial cervical morphological characteristics could not be undertaken because of the lack of long-term follow-up data. Thirdly, The lack of whole spine X-ray is also the limitation. Fourthly, the cervical spine was divided into lordosis and kyphosis groups, and S-type was not included in this study. The relationship between S-type and cervical spine alignment should be clarified in future studies. Lastly, objective was to demonstrate the special relationship in the upper and the subaxial cervical spine. However, the cervical malalignment may be affected by muscles and biomechanics. Therefore, future studies to clearly demonstrate this mechanism should be conducted.

\section{Conclusion}

In this study, the association between T1 slope and sagittal alignment parameters of the upper or subaxial cervical spine were found to differ between patients with cervical lordotic and kyphotic curvature. The two cervical alignment types (lordosis and kyphosis) have different angular variation in upper and subaxial cervical spine. With increase in T1 slope, the upper cervical C0-C2 Cobb angle and the C2-7 SVA in the lordotic group was significantly higher than that in the kyphotic group, which indicates that subaxial cervical lordosis plays an important role in the maintenance of total cervical balance and horizontal gaze. Consistent with the trend observed in the lumbosacral spine, TS-CL mismatch may significantly impact lordotic cervical alignment. 


\section{List Of Abbreviations}

Standard deviation (SD)

One-way Analysis of Variance (ANOVA)

\section{Declarations}

\section{Ethics approval and consent to participate}

The experimental protocol was established, according to the ethical guidelines of the Helsinki Declaration and was approved by the institutional ethics review Board of China-Japan union hospital of Jilin University. Written informed consent was obtained from individual participants.

\section{Competing interests}

None

Funding

No funding was obtained for this study

\section{Authors' contributions}

SD designed the study, conducted all searches, appraised all potential studies and wrote and revised the draft manuscript and subsequent manuscripts. LP revised the draft manuscript and subsequent manuscripts. WZL and CJ assisted with the presentation of findings and assisted with drafting and revising the manuscript. MJH, TFH, LS, BHM, SN, WYP conceived and designed the study, assisted with searches, appraised relevant studies and assisted with drafting and revising the manuscript. All authors read and approved the final manuscript.

\section{Acknowledgments}

No funds were received in support of this work. No benefits in any form have been or will be received from a commercial party related directly or indirectly to the subject of this manuscript

\section{References}

1. Hayashi T, Daubs MD, Suzuki A et al. (2016) The Compensatory Relationship of Upper and Subaxial Cervical Motion in the Presence of Cervical Spondylosis. Clin Spine Surg 29 (4):E196-200. doi:10.1097/BSD.0b013e3182aab240

2. Scheer JK, Tang JA, Smith JS et al. (2013) Cervical spine alignment, sagittal deformity, and clinical implications: a review. J Neurosurg Spine 19 (2):141159. doi:10.3171/2013.4.SPINE12838

3. Toyama Y, Matsumoto M, Chiba K et al. (1994) Realignment of postoperative cervical kyphosis in children by vertebral remodeling. Spine (Phila Pa 1976) 19 (22):2565-2570

4. Lee SH, Kim KT, Seo EM et al. (2012) The influence of thoracic inlet alignment on the craniocervical sagittal balance in asymptomatic adults. J Spinal Disord Tech 25 (2):E41-47. doi:10.1097/BSD.0b013e3182396301

5. Yang BS, Lee SK, Song KS et al. (2015) The Use of T1 Sagittal Angle in Predicting Cervical Disc Degeneration. Asian Spine J 9 (5):757-761. doi:10.4184/asj.2015.9.5.757

6. Ordway NR, Seymour RJ, Donelson RG et al. (1999) Cervical flexion, extension, protrusion, and retraction. A radiographic segmental analysis. Spine (Phila Pa 1976) 24 (3):240-247

7. Lafage R, Challier V, Ferrero E et al. (2014) Validation of correlation between CBVA, SLS, and McGregor's Slope. Spine Journal 14 (11):S138-S139

8. Lafage R, Challier V, Ferrero E et al. Validation of correlation between CBVA, SLS, and McGregor's Slope. In: Srs Meeting, 2014. pp S138-S139

9. Le Huec JC, Demezon H, Aunoble S (2015) Sagittal parameters of global cervical balance using EOS imaging: normative values from a prospective cohort of asymptomatic volunteers. Eur Spine J 24 (1):63-71. doi:10.1007/s00586-014-3632-0

10. Yukawa Y, Kato F, Suda K et al. (2012) Age-related changes in osseous anatomy, alignment, and range of motion of the cervical spine. Part I: Radiographic data from over 1,200 asymptomatic subjects. Eur Spine J 21 (8):1492-1498. doi:10.1007/s00586-012-2167-5

11. Yu M, Zhao WK, Li M et al. (2015) Analysis of cervical and global spine alignment under Roussouly sagittal classification in Chinese cervical spondylotic patients and asymptomatic subjects. Eur Spine J 24 (6):1265-1273. doi:10.1007/s00586-015-3832-2

12. Barrey C, Roussouly P, Le Huec JC et al. (2013) Compensatory mechanisms contributing to keep the sagittal balance of the spine. Eur Spine $\mathrm{J} 22$ Suppl 6:S834-841. doi:10.1007/s00586-013-3030-z

13. Yoshimoto $\mathrm{H}$, Ito $\mathrm{M}$, Abumi $\mathrm{K}$ et al. (2004) A retrospective radiographic analysis of subaxial sagittal alignment after posterior $\mathrm{C} 1-\mathrm{C} 2$ fusion. Spine (Phila Pa 1976) 29 (2):175-181. doi:10.1097/01.BRS.0000107225.97653.CA

14. Matsunaga S, Onishi T, Sakou T (2001) Significance of occipitoaxial angle in subaxial lesion after occipitocervical fusion. Spine (Phila Pa 1976) 26 (2):161-165 
15. Hyun SJ, Kim KJ, Jahng TA et al. (2016) Relationship Between T1 Slope and Cervical Alignment Following Multilevel Posterior Cervical Fusion Surgery: Impact of T1 Slope Minus Cervical Lordosis. Spine (Phila Pa 1976) 41 (7):E396-402. doi:10.1097/BRS.0000000000001264

16. Tang JA, Scheer JK, Smith JS et al. (2015) The Impact of Standing Regional Cervical Sagittal Alignment on Outcomes in Posterior Cervical Fusion Surgery. Neurosurgery 76 (suppl_1):S14-S21. doi:10.1227/01.neu.0000462074.66077.2b

17. The design evolution of interbody cages in anterior cervical discectomy and fusion: a systematic review

\section{Figures}

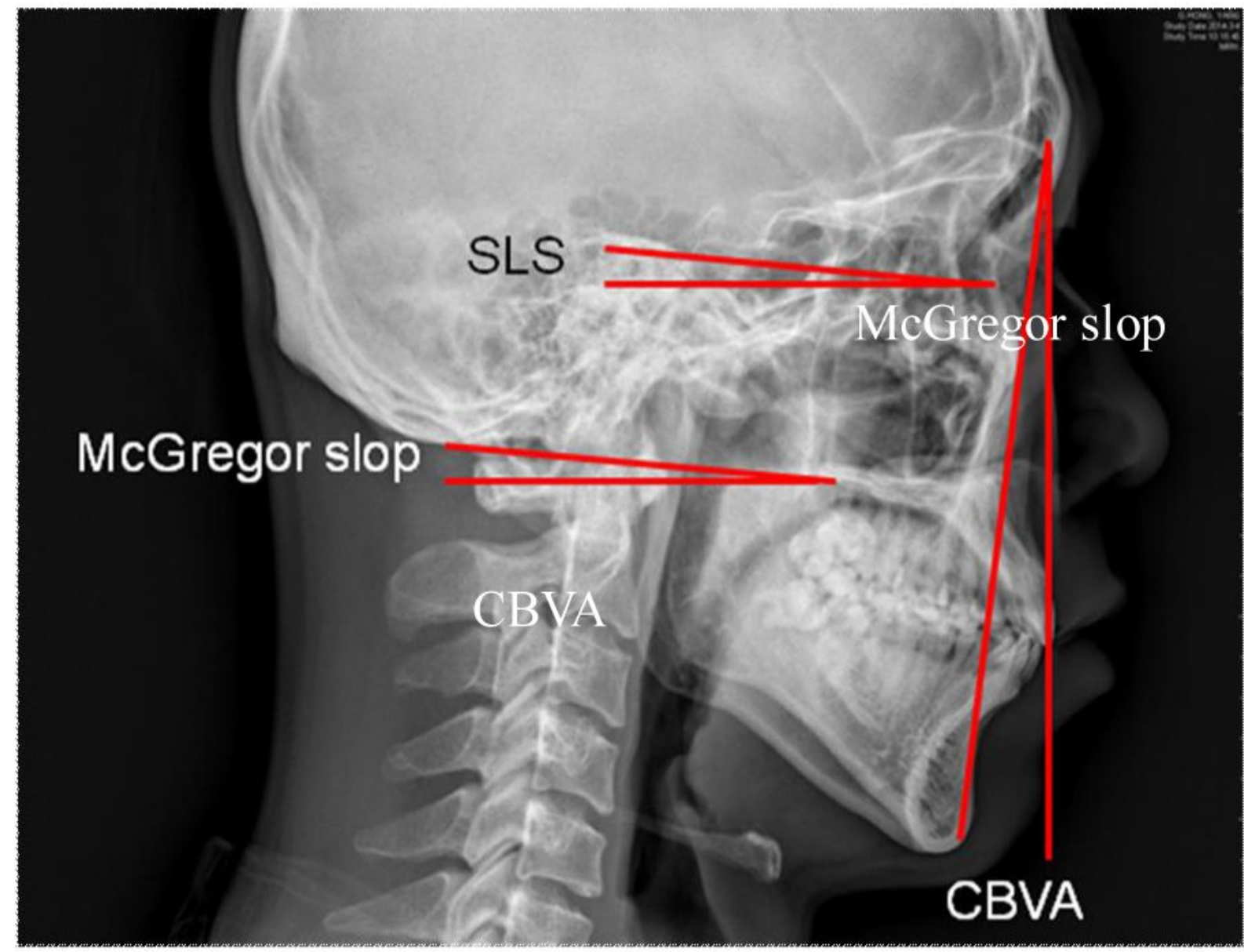

\section{Figure 1}

Illustration of the horizontal gaze parameters McGS is the angle subtended by a line joining the postero-superior aspect of the hard palate with the caudal aspect of the opisthion with the horizontal plane. SLS is the slope of line of sight; angle between Frankfurt line and the horizontal. CBVA is chin brow vertical angle, which is the angle subtended by the line joining the brow to the chin with the vertical plane. 

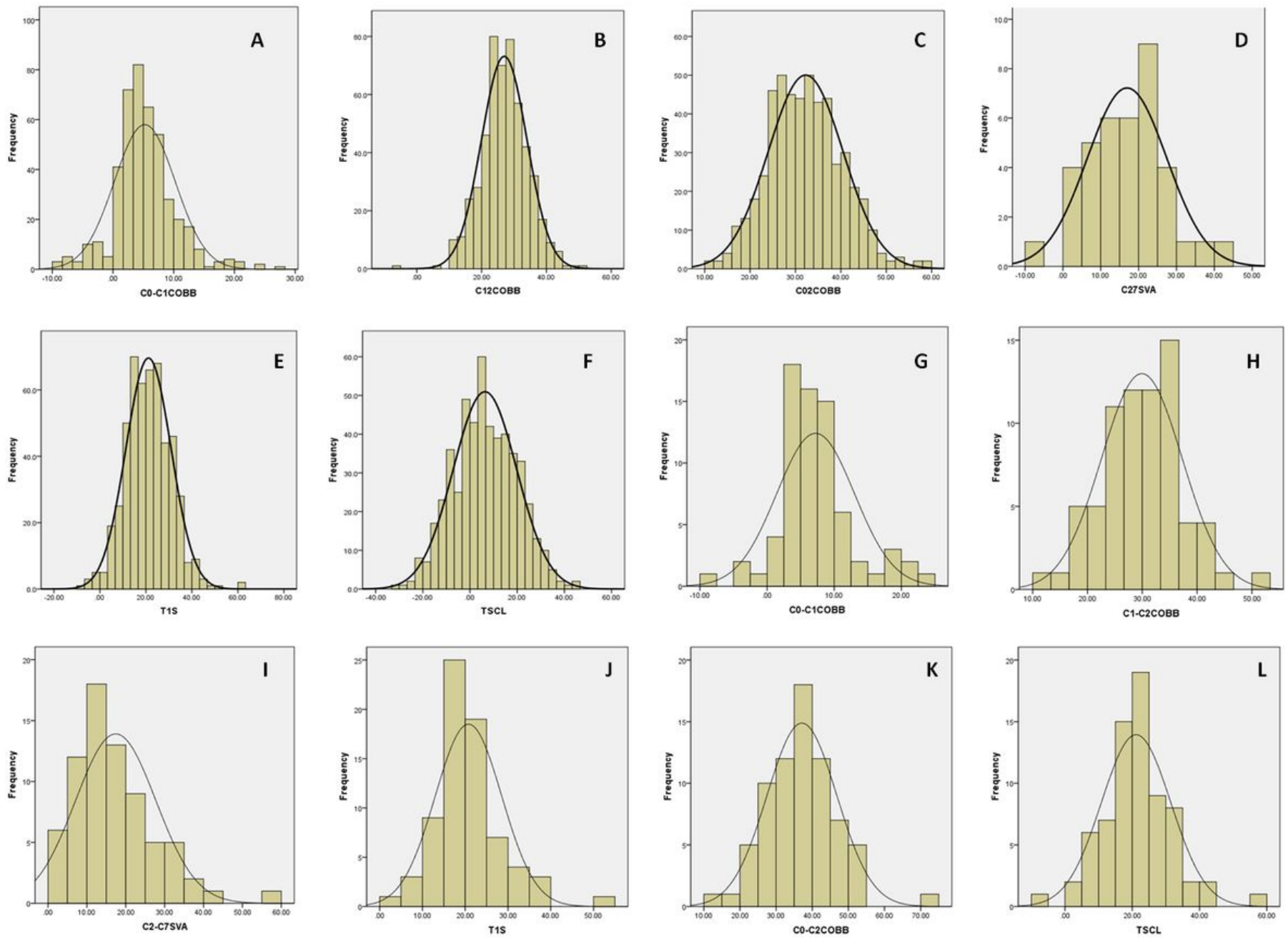

Figure 2

Distribution of the radiographic parameters (A and G), CO-C1COBB; (B and H), C1-C2COBB; (C and K), C0-C2COBB; (D and I), C2-7SVA; (E and J), T1S; (F and L), TS-CL. 

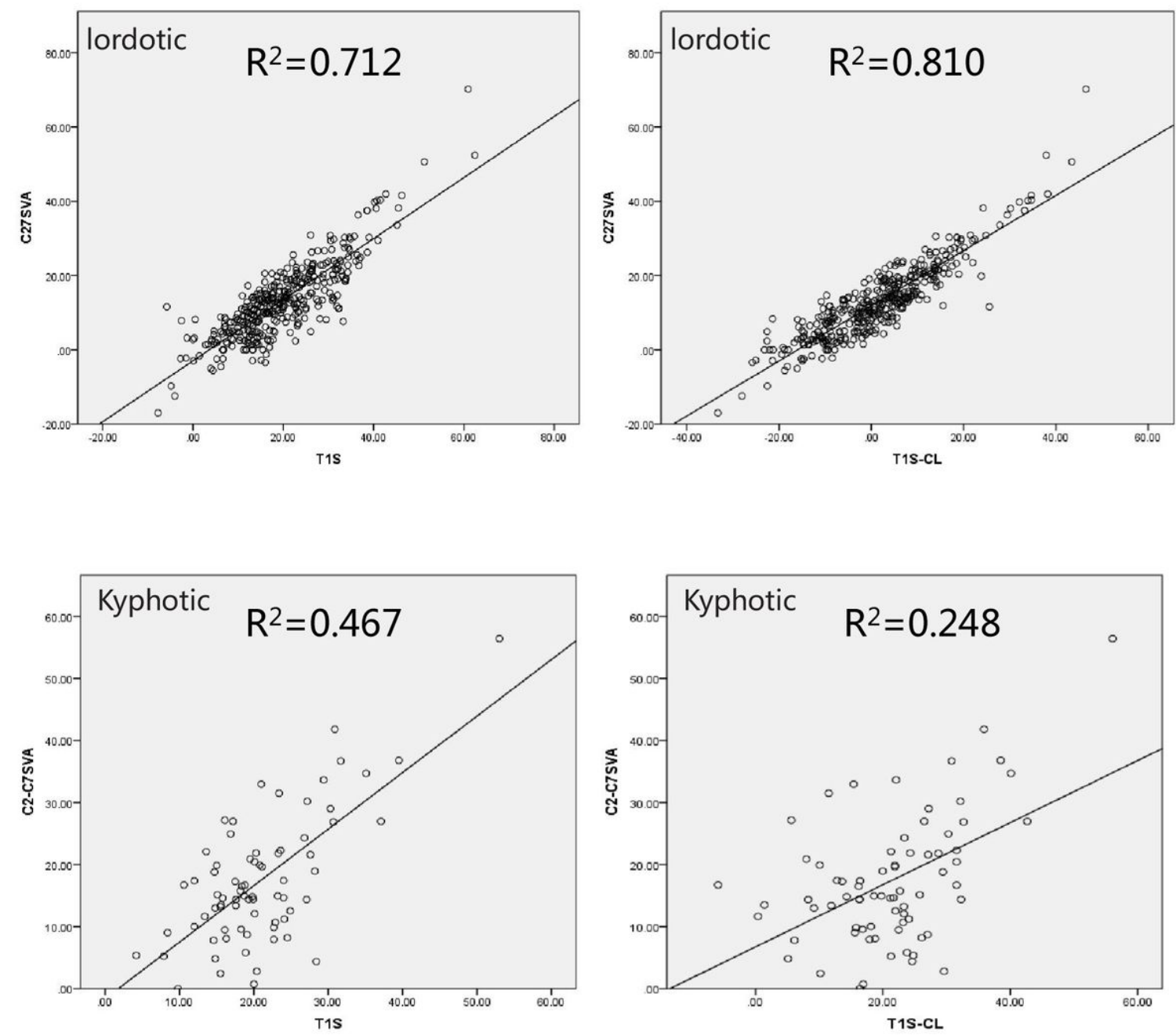

\section{Figure 3}

Results of linear regression analysis showing statistically significant correlation between radiographic parameters in the lordotic and kyphotic groups (A, C), C2-C7SVA versus T1S; (B, D), C2-C7SVA versus TS-CL. 